\title{
Maxillofacial Nursing: Assessing the Knowledge and Awareness of Nurses in Handling Maxillofacial Injuries Through a Comprehensive Survey
}

\author{
Nishit Kumar ${ }^{1} \cdot$ Rama Shankar Choudhary $^{2} \cdot$ Kamal Malhotra $^{3} \cdot$ Rahul Kathariya $^{4}(\mathbb{D}$
}

Received: 23 January 2017/ Accepted: 13 May 2019/Published online: 14 June 2019

(C) The Association of Oral and Maxillofacial Surgeons of India 2019

\begin{abstract}
Aim To assess the knowledge and awareness of nurses in handling maxillofacial injuries.

Method A cross-sectional questionnaire study was conducted among the staff nurses of the multi-specialty Gokul Newtech Hospital, Jamnagar, Gujarat. Forty nursing staff were included in the study. Kruskal-Wallis ANOVA, Spearman's correlation and Mann-Whitney $U$ tests were applied for statistical analysis.

Result There was no statistically significant difference between the mean knowledge score concerning the study participant's age, work experience, and education. According to the survey, a majority of the nurses either did not know the answer or answered incorrectly.

Conclusion It can be concluded that there is a requirement of new guidelines and recommendations in the existing teaching and training modules being followed by the nursing schools across the country.
\end{abstract}

Electronic supplementary material The online version of this article (https://doi.org/10.1007/s12663-019-01240-x) contains supplementary material, which is available to authorized users.

Rahul Kathariya

rkathariya@gmail.com

1 Department of Oral and Maxillofacial Surgery, Government Dental College and Hospital, Jamnagar, Gujarat, India

2 Department of Dentistry, Tata Main Hospital, Jamshedpur, UP, India

3 Dr. Malhotra's Nuface Clinic, 1813 Maharaja Nagar, Ludhiana, Punjab, India

4 Dental Galaxy, 201, 1st floor, 1443 Kaustubh Apts, Bajirao Road, Pune, Maharashtra 411002, India
Keywords Maxillofacial injuries · Nursing assistants · Oral surgical procedure $\cdot$ School $\cdot$ Nursing $\cdot$ Nursing assessment $\cdot$ Nursing audits

\section{Introduction}

Complete patient care is not possible without having proper systematic and comprehensive nursing care for any patient who is admitted to a hospital for any illness. Nursing education in India is limited to medical hospitals and is routinely taught by medical doctors. Thereby, nurses do not get any exposure to dental/maxillofacial procedures. The Indian Nursing Council also does not have a syllabus designed for nursing students that includes dental/maxillofacial education. So when a patient is admitted for maxillofacial care, because of very limited understanding, lack of skills and knowledge pertaining to maxillofacial diseases, nurses feel helpless, and ultimately the entire care of the patient is either pushed to the maxillofacial surgeon or is ignored.

The maxillofacial skeleton is commonly fractured due to its prominent position. The location and pattern of the fractures are determined by the type of injury and the direction of impact. In addition, patient's age and the presence of teeth have a direct effect on the characteristic pattern of such injuries [1]. The incidence of maxillofacial injuries is on the rise due to the increase in the number of motor vehicle accidents. Road traffic accident (RTA) remains the most common cause of such injuries [2-4]. Maxillofacial injuries are unique because of the anatomical complexity of the area and their associated psychological effects [1].

Facial injury can occur in isolation or combination with injuries elsewhere. Regardless of the site of injury, there 
are local and systemic effects. An understanding of the cause of injury is important for several reasons. It helps to focus on the need for injury prevention. It may help to identify typical patterns of injury (e.g., the blow to the symphysis associated with a condylar fracture or head injury), and it may raise awareness of the risk of future injuries (for example, in cases of domestic violence) [5]. There are many unique features of injuries of the face because it is responsible for the senses of sight, smell, taste, and hearing [5]. In addition, eating, drinking, speech, and communication through facial expression depend on the integrity of maxillofacial structures. Disruption of the maxillofacial skeleton can also put airway at risk leading to respiratory emergency. In those with maxillofacial injuries, it is even necessary to consider the possibility that there may be an injury to the base of the skull, cranial vault, brain, the cervical spine or the upper aerodigestive tract $[5,6]$.

Road traffic accidents involve people of all ages, but most commonly young adults. In India, the incidences are increasing with growing population; more people are using motorized vehicles, and conditions of the roads are deteriorating. Twenty times more deaths are caused by road traffic accidents in India than in developed countries: Eight people are killed/100 vehicles, whereas, in developed countries, one person is killed/1000 vehicles [7]. Alcohol is an important factor in these accidents. Population-based data and studies on road traffic injuries in India are insufficient, and further research is needed. Understanding the various causes of these injuries will help us to prevent it and will enable countermeasures to be formulated $[8,9]$.

The management of fractures of the maxillofacial complex remains a challenge for the maxillofacial surgeon, demanding both skill and expertise. Epidemiological studies usually classify trauma according to anatomical site. Although this is logical for treatment in terms of developing strategies, it is more informative to consider etiology and the applied forces that produce the injuries $[10,11]$.

In India, there is a severe shortage of qualified doctors and specialists to manage maxillofacial injuries, so we need to have more efficient and versatile nurses and paramedics to handle such cases in rural as well as urban areas. Very few studies have been done to assess the awareness of dental injuries among the medical practitioners and nurses and have concluded that the understanding is very limited and inadequate. Till date, no such study is undertaken to assess the knowledge and skills of nursing staff to manage the patients with maxillofacial injuries. Thus, in the following study, we aimed to assess the knowledge and awareness of nurses about maxillofacial injuries.

\section{Materials and Methods}

A cross-sectional questionnaire study among the staff nurses of the Gokul Newtech Hospital, Jamnagar, Gujarat, was undertaken. Ethical approval was obtained from the Institutional Ethical Committee \& Review Board. Convenience sampling method was followed in this study. A total of 40 staff nurses were involved in the study. A questionnaire was designed in simple English considering the basics of maxillofacial injuries. Nurses willing to participate voluntarily were included in the study. Nurses who did not have a valid nursing degree (M.Sc., B.Sc. or diploma), or unable to or incapable of completing the questionnaire survey, were excluded from the study.

The questionnaire was divided into two parts. Part I contained questions on personal information, part II contained questions based on knowledge and skills related to the maxillofacial injuries. The completed forms were compiled, and the data was entered into an MS Excel sheet, and descriptive statistics were calculated for demographic characteristics and responses generated by the study participants by percentages using IBM, SPSS Statistics version 22 .

To determine the differences in the mean knowledge and skills scores in relation to the work experiences, KruskalWallis ANOVA was performed at a significance level of $p<0.05$.

Similarly, the Spearman's correlation statistics were conducted to evaluate the relationship between the age, educational qualification, working experience, knowledge and skill scores. Further to evaluate the gender and educational qualification based differences in relation to their mean knowledge and skill scores, Mann-Whitney $U$ test was conducted at $p<0.05$.

\section{Results}

- $52.5 \%$ have a work experience of $<5$ years, $25 \%$ having $\geq 5$ but $<10$ years of experience, $12.5 \%$ were having $\geq 10$ but $<15$ years of experience, and only $10 \%$ were having $\geq 15$ years of work experience. 82.5 were bachelor's degree holders, and 17.5 were diploma holders (Tables 1, 2, 3, 4, 5).

Table 1 Educational qualification among nurses

\begin{tabular}{lrc}
\hline Educational qualification & $N$ & $\%$ \\
\hline B.Sc. & 33 & 82.5 \\
Diploma & 7 & 17.5 \\
\hline
\end{tabular}


Table 2 Work experience among nurses

\begin{tabular}{lrl}
\hline Work experience (years) & $n$ & $\%$ \\
\hline $1-5$ & 21 & 52.5 \\
$6-10$ & 10 & 25 \\
$11-15$ & 5 & 12.5 \\
$>15$ & 4 & 10 \\
\hline
\end{tabular}

- $92.5 \%$ did not have any additional training (Staff Education Program/training program/Continued Nursing Education), while $7.5 \%$ have had some additional training in the field related to maxillofacial specialty.

A Kruskal-Wallis test was conducted to observe the difference in the mean knowledge scores with reference to the participants' working experience at $p<0.05$. The results revealed that there is an increased knowledge level in participants having $>15$ years of working experience $($ mean $=2.5 \pm 0.58)$ and relatively lower mean knowledge scores for $11-15$ years $($ mean $=2.20 \pm 0.84)$ and $1-5$ years $($ mean $=2.19 \pm 0.81)$. The least mean knowledge score was observed in participants having 6-10 years of experience $(0.9 \pm 1.9)$. However, there was no statistically significant difference between the mean knowledge score with reference to the study participant's work experience $(p=0.773)$. Answers to the questionnaire are given in Tables 6 and 7.

\section{Discussion}

The study included 40 qualified nurses serving in the Gokul Newtech Hospital of Jamnagar Gujarat. The nurses were assessed with the help of a questionnaire for their knowledge and skill involving the nursing care of the patients with maxillofacial injuries.

Maxillofacial surgery is a relatively recent specialty of dentistry, and that is why the scope and capabilities of this
Table 4 Spearman's correlation statistics to check the relationship between work experience, knowledge, and the skill scores

\begin{tabular}{llll}
\hline Variables & Work experience & MKS & MSS \\
\hline Work experience & & & \\
$\quad$ Spearman's rho & 1 & 0.083 & 0.176 \\
$p$ value & & 0.611 & 0.279 \\
$N$ & 40 & 40 & 40 \\
MKS & & & \\
Spearman's rho & 0.083 & 1 & 0.309 \\
$p$ value & 0.611 & & 0.052 \\
$N$ & 40 & 40 & 40 \\
MSS & & & \\
Spearman's rho & 0.176 & 0.309 & 1 \\
$p$ value & 0.279 & 0.052 & \\
$N$ & 40 & 40 & 40 \\
\hline
\end{tabular}

specialty remain unclear to many health care workers including nurses. In our study, only $42.5 \%$ knew that this is a branch of dentistry while rest of the participants were not aware of this specialty, so it shows that the knowledge of this specialty is not widespread and clear among the nursing staff.

A similar survey conducted by Rohit Sharma et al. evaluated the awareness of oral and maxillofacial surgery among medical practitioners in North India. The authors concluded that out of 462 medical practitioners, only $20.78 \%$ had ever consulted/referred a patient to an oral and maxillofacial surgeon [12].

Another study by Ameerally et al. showed that $79 \%$ of the general population had not heard of OMFS, and around $74 \%$ did not understand its role and scope [13].

Lau SL in 2014 did a survey study to analyze the public awareness regarding the specialty of OMFS in Hong Kong. He concluded that among the 104 interviewees there were $78(75 \%)$ who claimed they had never heard of it [14]. Subhashraj and Subramaniam did a survey study in 2006,

Table 3 Comparison of mean knowledge and skill score with the work experience using Kruskal-Wallis ANOVA

\begin{tabular}{|c|c|c|c|c|c|c|c|c|c|c|}
\hline \multirow[t]{2}{*}{ Variable } & \multirow[t]{2}{*}{ Work exp (years) } & \multirow[t]{2}{*}{$N$} & \multirow[t]{2}{*}{ Mean } & \multirow[t]{2}{*}{$\mathrm{SD}$} & \multirow[t]{2}{*}{ SE } & \multicolumn{2}{|c|}{$95 \% \mathrm{Cl}$ for mean } & \multirow[t]{2}{*}{ Min } & \multirow[t]{2}{*}{$\operatorname{Max}$} & \multirow[t]{2}{*}{$p$ value } \\
\hline & & & & & & Lower & Upper & & & \\
\hline \multirow[t]{4}{*}{ Mean Knowledge Score } & $1-5$ & 21 & 2.19 & 0.81 & 0.18 & 1.82 & 2.56 & 1 & 4 & \multirow[t]{4}{*}{0.773} \\
\hline & $6-10$ & 10 & 2.1 & 0.88 & 0.28 & 1.47 & 2.73 & 1 & 4 & \\
\hline & $11-15$ & 5 & 2.2 & 0.84 & 0.37 & 1.16 & 3.24 & 1 & 3 & \\
\hline & $>15$ & 4 & 2.5 & 0.58 & 0.29 & 1.58 & 3.42 & 2 & 3 & \\
\hline \multirow[t]{4}{*}{ Mean Skill Score } & $1-5$ & 21 & 1.1 & 0.94 & 0.21 & 0.67 & 1.52 & 0 & 3 & \multirow[t]{4}{*}{0.431} \\
\hline & $6-10$ & 10 & 1 & 1.25 & 0.39 & 0.11 & 1.89 & 0 & 4 & \\
\hline & $11-15$ & 5 & 1.8 & 0.84 & 0.37 & 0.76 & 2.84 & 1 & 3 & \\
\hline & $>15$ & 4 & 1.5 & 1.73 & 0.87 & -1.26 & 4.26 & 0 & 3 & \\
\hline
\end{tabular}

*Statistical significance at $p<0.05$ 
Table 5 Comparison of mean knowledge and skill scores based on their educational qualification using Mann-Whitney $U$ test

\begin{tabular}{|c|c|c|c|c|c|c|c|c|c|c|c|}
\hline \multirow[t]{2}{*}{ Variables } & \multirow[t]{2}{*}{ Edu Quali } & \multirow[t]{2}{*}{$N$} & \multirow[t]{2}{*}{ Mean } & \multirow[t]{2}{*}{ SD } & \multirow[t]{2}{*}{ SE } & \multirow[t]{2}{*}{ Mean diff } & \multicolumn{2}{|c|}{$95 \% \mathrm{Cl}$ of the diff } & \multirow[t]{2}{*}{$d f$} & \multirow[t]{2}{*}{$z$} & \multirow[t]{2}{*}{$p$ Value } \\
\hline & & & & & & & Lower & Upper & & & \\
\hline \multirow[t]{2}{*}{ MKS } & B.Sc. & 33 & 2.21 & 0.86 & 0.15 & 0.07 & -0.61 & 0.74 & 38 & -0.212 & 0.832 \\
\hline & Diploma & 7 & 2.14 & 0.38 & 0.14 & & & & & & \\
\hline \multirow[t]{2}{*}{ MSS } & B.Sc & 33 & 1.24 & 1.15 & 0.20 & 0.24 & -0.69 & 1.17 & 38 & -0.371 & 0.711 \\
\hline & Diploma & 7 & 1 & 0.82 & 0.309 & & & & & & \\
\hline
\end{tabular}

*Statistical significance at $p<0.05$

Table 6 Opinion (\%) of nurses for different questions

\begin{tabular}{lllll}
\hline Questions & Option A (\%) & Option B (\%) & Option C (\%) & Option D (\%) \\
\hline 1 & 30 & 42.5 & 5 & 22.5 \\
2 & 5 & - & 7.5 & 87.5 \\
3 & 70 & 12.5 & 5 & 12.5 \\
4 & 20 & 70 & 10 & - \\
5 & 77.5 & 5 & - & 17.5 \\
6 & 7.5 & 15 & 12.5 & 65 \\
7 & 40 & 35 & 5 & 20 \\
8 & 22.5 & 42.5 & 35 & - \\
9 & 37.5 & 40 & 15 & 7.5 \\
10 & 10 & 90 & - & - \\
11 & 2.5 & 97.5 & - & - \\
12 & 20 & 80 & - & - \\
13 & 2.5 & 97.5 & - & - \\
14 & 15 & 85 & - & \\
\hline
\end{tabular}

to establish the knowledge level among dental, medical, and paramedical professionals of the hospital. The survey analyzed the role of oral and maxillofacial surgery in health care and concluded that only $41 \%$ of the medical students, $76 \%$ of medical practitioners, and $58 \%$ of the paramedical workers had heard the name of the specialty [15].

In individuals below the age of 45 years, it has been observed that the primary cause of death in the USA and developing countries is a road traffic injury. Maxillofacial injuries are very commonly seen cases in the emergency room setups [16]. This is the reason why it is cardinal to provide quick assistance to the specialist in treating such patients. This also accounts for nurses being trained and well informed about procedures being performed by the specialist so that they can quickly prepare when encountering one. When asked during the survey only 5\% responded correctly demonstrating that either they have not seen maxillofacial injuries in the emergency room or never assisted one.

The following question was about the most commonly associated injury, and $70 \%$ gave a correct response which was a statistically significant response. This indicated that the majority of the nurses were aware that an injury to the face should be evaluated for a head injury. When asked about the treatment to be given in the absence of specialist, only $20 \%$ were able to give a correct answer.

One question was asked to assess the knowledge regarding the most commonly needed instruments to be kept at bedside, for that only $7.5 \%$ answered it correctly. In maxillofacial trauma, there is a high risk of concomitant cervical spine or spinal cord injury. It might be due to transmission of force from the skull to the cervical spine [17]. To avoid spinal cord injury after Maxillofacial trauma, only $40 \%$ of the staff knew the correct method to avoid cervical injury.

Dental plaque is a dynamic and complex system that associates microorganisms embedded in an extracellular matrix. Dental plaque predominates on the subgingival and supragingival surfaces of teeth, but without mechanical elimination, it can cover the entire tooth surface. In a recent systematic review, Scannapieco et al. identified 11 clinical studies demonstrating a significant association between periodontal disease and the occurrence of nosocomial infections. Elderly, institutionalized, chronic obstructive pulmonary disease patients or intensive care unit (ICU) patients are at higher risk of periodontal colonization by nosocomial pathogens, because of difficulties in oral 
Table 7 Questionnaire with variables and its Chi-square and p value

\begin{tabular}{|c|c|c|c|c|c|}
\hline Sl. & Question & Variable & Total & Chi-square value & $p$ value \\
\hline 1. & According to you, maxillofacial surgery is & $\begin{array}{l}\text { Correct } \\
\text { Incorrect } \\
\text { Don't know }\end{array}$ & $\begin{array}{l}42.5 \% \\
35 \% \\
22.5 \%\end{array}$ & 2.450 & 0.294 \\
\hline 2. & $\begin{array}{l}\text { What is the most common emergency procedure is done by } \\
\text { the maxillofacial surgeon in case of fractured mandible }\end{array}$ & $\begin{array}{l}\text { Correct } \\
\text { Incorrect } \\
\text { Don't know }\end{array}$ & $\begin{array}{l}5 \% \\
4.5 \% \\
87.5\end{array}$ & 52.850 & $<0.001^{*}$ \\
\hline 3. & $\begin{array}{l}\text { What is the most common injury associated along with the } \\
\text { maxillofacial injuries? }\end{array}$ & $\begin{array}{l}\text { Correct } \\
\text { Incorrect } \\
\text { Don't know }\end{array}$ & $\begin{array}{l}70 \% \\
17.5 \% \\
12.5\end{array}$ & 24.350 & $<0.001 *$ \\
\hline 4. & $\begin{array}{l}\text { How will you stabilize the jaws of the patient who has } \\
\text { sustained a maxillofacial fracture in the absence of any } \\
\text { doctor or specialist }\end{array}$ & $\begin{array}{l}\text { Correct } \\
\text { Incorrect } \\
\text { Don't know }\end{array}$ & $\begin{array}{l}20 \% \\
80 \% \\
-\end{array}$ & 24.800 & $<0.001 *$ \\
\hline 5. & $\begin{array}{l}\text { In a patient with maxillofacial injuries, the diet should be } \\
\text { given in which form preferably }\end{array}$ & $\begin{array}{l}\text { Correct } \\
\text { Incorrect } \\
\text { Don't know }\end{array}$ & $\begin{array}{l}77.5 \% \\
5 \% \\
17.5\end{array}$ & 36.050 & $<0.001^{*}$ \\
\hline 6. & $\begin{array}{l}\text { What are the most common instruments to be kept at the } \\
\text { bedside to the patient who is operated for maxillofacial } \\
\text { injuries }\end{array}$ & $\begin{array}{l}\text { Correct } \\
\text { Incorrect } \\
\text { Don't know }\end{array}$ & $\begin{array}{l}7.5 \% \\
27.5 \% \\
65 \%\end{array}$ & 20.450 & $<0.001 *$ \\
\hline 7. & $\begin{array}{l}\text { In an unconscious patient with maxillofacial injuries is } \\
\text { attended by you 1st then what care you will take to avoid } \\
\text { spinal cord injury }\end{array}$ & $\begin{array}{l}\text { Correct } \\
\text { Incorrect } \\
\text { Don't know }\end{array}$ & $\begin{array}{l}40 \% \\
40 \% \\
20\end{array}$ & 3.200 & 0.202 \\
\hline 8. & $\begin{array}{l}\text { In ICU what care you will take to prevent salivary gland } \\
\text { infection }\end{array}$ & $\begin{array}{l}\text { Correct } \\
\text { Incorrect } \\
\text { Don't know }\end{array}$ & $\begin{array}{l}22.5 \% \\
77.5 .5 \% \\
-\end{array}$ & 2.450 & 0.294 \\
\hline 9. & $\begin{array}{l}\text { Whom do you think should be the most appropriate } \\
\text { specialist to treat maxillofacial injuries }\end{array}$ & $\begin{array}{l}\text { Maxillofacial surgeons } \\
\text { Plastic surgeons } \\
\text { ENT surgeons } \\
\text { General surgeons }\end{array}$ & $\begin{array}{l}30 \% \\
45 \% \\
15 \% \\
10 \%\end{array}$ & 12.600 & $0.006^{*}$ \\
\hline 10. & Are you aware of the term teeth occlusion & $\begin{array}{l}\text { Yes } \\
\text { No }\end{array}$ & $\begin{array}{l}10 \% \\
90 \%\end{array}$ & 25.600 & $<0.001 *$ \\
\hline 11. & $\begin{array}{l}\text { You feel you are well trained to take nursing care of } \\
\text { maxillofacial injuries including preoperative, } \\
\text { intraoperative, and postoperative care }\end{array}$ & $\begin{array}{l}\text { Yes } \\
\text { No } \\
\text { Some Extent }\end{array}$ & $\begin{array}{l}2.5 \% \\
90 \% \\
7.5 \%\end{array}$ & 57.950 & $<0.001 *$ \\
\hline 12. & $\begin{array}{l}\text { You aware of various measure to maintain oral hygiene for } \\
\text { a patient with inter-maxillary fixation }\end{array}$ & $\begin{array}{l}\text { Yes } \\
\text { No }\end{array}$ & $\begin{array}{l}20 \% \\
80 \%\end{array}$ & 14.400 & $<0.001^{*}$ \\
\hline 13. & $\begin{array}{l}\text { Can you identify the various forceps for extraction of the } \\
\text { tooth }\end{array}$ & $\begin{array}{l}\text { Yes } \\
\text { No }\end{array}$ & $\begin{array}{l}2.5 \% \\
97.5 \%\end{array}$ & 36.100 & $<0.001^{*}$ \\
\hline 14. & $\begin{array}{l}\text { Are you aware of the physiotherapy required in the } \\
\text { postoperative phases for the mandibular condyle fractures }\end{array}$ & $\begin{array}{l}\text { Yes } \\
\text { No }\end{array}$ & $\begin{array}{l}15 \% \\
85 \%\end{array}$ & 19.600 & $<0.001^{*}$ \\
\hline
\end{tabular}

hygiene, changes in salivary properties, and reduction in anaerobic flora [8-10]. Genuit et al. studied the effect of a prophylactic chlorhexidine oral rinse in 95 surgical ICU patients, compared with historical controls. They showed that the addition of oral care to a protocol of weaning from mechanical ventilation led to a significant reduction in lateonset ventilator-associated pneumonia (VAP) [18]. It is critical for nurses in ICU to provide adequate oral hygiene care to the patient to reduce the nosocomial infection-related morbidity and mortality. To assess their awareness about this, we asked them that what care you will take to reduce the probability of nosocomial infections, and only $22.5 \%$ gave the correct response, while others think that there is no special care is required and it is not the job of the nursing staff. 
As the maxillofacial specialty is relatively recent, it is quite natural for nurses not to have knowledge of it. This question was asked to know their perspective on the most appropriate specialist to provide the definitive care to the maxillofacial trauma, and 30\% responded in favor of maxillofacial surgeons, $45 \%$ responded in favor of plastic surgeons, $15 \%$ responded in favor of ENT surgeons, and only $10 \%$ responded in favor of general surgeons which indicates that for them maxillofacial and plastic surgery speciality is quite similar and overlapping in providing the care.

The most important clinical sign to be considered in planning as well as assessing the severity of the maxillofacial injury is the 'teeth occlusion' [19] and that is why it is very important to have clinical knowledge about it for every nursing staff. This is why a question was askedwhether or not they are aware of the term 'maxillofacial', and to our surprise $90 \%$ were unaware. They were also asked about the knowledge of various oral hygiene maintenance measures, and we got a positive response only from $20 \%$ of the participants.

Maxillofacial injuries involving temporomandibular joint also needs special consideration in terms of postoperative care, and like all the other synovial joints, this joint can also undergo post-traumatic arthropathy and subsequently ankylosis of the joint [20]. So the postoperative nursing care involves active physiotherapy of the jaw muscles to maintain the adequate function of the joint. So, nurses must be aware of the basics of exercises as prescribed by the surgeon. In our study, we got a positive response only from $15 \%$ of the participants.

The curriculum designed by the Indian Nursing Council for graduate, postgraduate, and diploma courses in nursing and midwifery [21] quotes 'dental' as a facility for clinical experience in the section 'Other Specialties' (p. 21) and has no mandatory requirements. Lists 'dental caries' in the nursing management of patients with gastrointestinal diseases (p. 78). Includes 'dental health' in 'school age' under 'Child Health Nursing' syllabus for 2nd year curriculum (p. 104). It is very sad that the premier institute for nursing mentions the word 'dental' only three times in their entire syllabus of 132 pages. There is no mention of words like 'maxillofacial' 'maxilla' or 'mandible' nor is the curriculum designed for continued nursing education. Such is the state and fate of nursing students in our country.

In our study, we found that only $20 \%$ of the participants felt that they are well trained to provide nursing care to the patients with maxillofacial injuries. This may be attributed to a lack of training to the nurses in this area as well as exposure to these types of injuries.

Nursing education is not able to catch pace with fast innovating medical and dental fields. With this study, we urge the nursing fraternity, and the Indian nursing council to regulate a syllabus which includes thorough knowledge of nursing for dental and maxillofacial injuries and regulate certain guidelines for continued nursing education in the oral and maxillofacial specialty.

Although the sample size in this study is small, and it is a single-centric study, and this is the first study of its type to assess the knowledge and awareness of the nurses regarding maxillofacial injuries, and data can be considered for further large multicentric studies to formulate guidelines and syllabus in nursing courses in our country.

\section{Conclusions}

There is a need for greater awareness, validated guidelines, and training resources for nurses to provide proper and adequate nursing care to the maxillofacial trauma patients.

Further, multicentric studies with large sample sizes involving different types of hospitals are warranted to support and validate our findings. The study can be considered as a pilot study for a future large database study which can give the correct scenario of the awareness of nurses in the field of maxillofacial speciality, and thereby, if required, new guidelines and recommendations can be outlined for the required modifications in the existing teaching and training modules being followed by the nursing schools across the country.

\section{Compliance with Ethical Standards}

Conflict of interest The authors report no conflict of interest.

\section{References}

1. Eberad K, Schilli W (1982) Oral and maxillofacial traumatology. Chicago Quintessence Publishing Co, Chicago, pp 308-370

2. Thoma KH (1969) Fracture of mandible. In: Oral surgery, vol 1, 5th edn. C.V. Mosby Company Ltd, pp 524-571

3. Fonseca Raymond J (1991) Oral and maxillofacial trauma, vol 1, 2nd edn. W B Saunders Company, Pennsylvania, pp 359-414

4. Fonseca Raymond J (2005) Oral and maxillofacial trauma, vol 2, 3rd edn. Elsevier Saunders Company, Pennsylvania, pp 1132-1164

5. Brickley MR, Shepherd JP (1995) The relationship between alcohol intoxication, injury severity, and Glasgow Coma Score. Injury 26:311-314

6. Harrison MG, Shepherd JP (1999) The circumstances and scope for prevention of maxillofacial injuries in cyclists. J R Coll Surg Edinb 44:82-86

7. World Health Organization. World health day theme-2004. Last cited on 2004. Available from: http://www. worldhealthorganization

8. Naveen A, Naveen V, Hegde N, Prasad R (2012) The pattern of the maxillofacial fractures e A multicentre retrospective study $q$. J Cranio-Maxillofac Surg 40(8):675-679 
9. Lindquist C, Kanto R, Antti Pihakari A et al (1986) Rigid Internal fixation of mandibular fractures-an analysis of 45 patients treated according to the ASIF method. Int J Oral Max Fac Surg 15:657-664

10. Ellis E (1993) Rigid skeletal fixation of fractures. J Oral and maxillofac Surg 51:163-173

11. Ardekian DR, Klein Y, Peled M, Michaelson M, Laufer D (1998) Life-threatening complications and irreversible damage following maxillofacial trauma. Injury 29:253-256

12. Sharma R, Atri G, Verma M (2015) Awareness of oral and maxillofacial surgery among medical practitioners in North India: a survey. J Postgrad Med Edu Res 49(2):70-73

13. Ameerally P, Fordyce AM, Martin IC (1994) So you think they know what we do public and professional perception of oral and maxillofacial surgery. Br J Oral Maxillofac Surg 32(3):142-145

14. Lau SL (2014) Do you think they know about us? Oral and maxillofacial surgery in Hong Kong. J Dent Health Oral Disord Ther 1(2):00011

15. Subhashraj K, Subramaniam B (2008) Awareness of the specialty of oral and maxillofacial surgery among health care professionals in Pondicherry, India. J Oral Maxillofac Surg 66(11):2330-2334
16. Bruns J Jr, Hauser WA (2003) The epidemiology of traumatic brain injury: a review. Epilepsia 44(Suppl 10):2-10

17. Mukherjee S, Abhinav K, Revington PJ (2015) A review of cervical spine injury associated with the maxillofacial trauma A at a UK tertiary referral center. Ann R Coll Engl 97(1):66-72

18. Ellis Edward, Walker Lee R (1994) Treatment of mandibular angle fractures using two noncompression mini plates. J Oral Maxillofac Surg 52:1032-1036

19. Rangarajan V, Gajapathi B, Yogesh PB, Ibrahim MM, Kumar RG, Karthik P (2015) Concepts of occlusion in prosthodontics: a literature review, part I. J Indian Prosthodont Soc 15(3):200-205

20. Yun PY, Kim YK (2005) The role of facial trauma as the possible etiologic factor in temporomandibular joint disorder. J Oral Maxillofac Surg 63(11):1576-1583

21. http://www.indiannursingcouncil.org/pdf/Syllabus_and\%20_Reg ulation_GNM_2015_WebPage.pdf

Publisher's Note Springer Nature remains neutral with regard to jurisdictional claims in published maps and institutional affiliations. 